\title{
Assessment of transit transport corridor efficiency \\ of landlocked African countries using data envelopment analysis
}

AUTHORS:

Enagnon H. Fanou ${ }^{1}$ iD

Xuping Wang ${ }^{1}$

\section{AFFILIATION: \\ ${ }^{1}$ School of Management \\ Science and Engineering, \\ Dalian University of Technology, \\ Dalian, China}

\section{CORRESPONDENCE TO: \\ Enagnon Fanou}

EMAIL:

fanoufabrice@yahoo.fr

\section{DATES:}

Received: 11 Nov. 2016

Revised: 23 Mar. 2017

Accepted: 13 Oct. 2017

\section{KEYWORDS:}

DEA; trade; comparative analysis; transport systems; technical efficiency; scale efficiency

\section{HOW TO CITE:}

Fanou EH, Wang X. Assessment of transit transport corridor efficiency of landlocked African countries using data envelopment analysis. S Afr J Sci. 2018;114(1/2), Art. \# 2016-0347, 7 pages. http://dx.doi.org/10.17159/ sajs.2018/20160347

\section{ARTICLE INCLUDES:}

$\checkmark$ Supplementary material

$\times$ Data set

\section{FUNDING:}

National Natural Science

Foundation of China (grant nos. 71471025,71421001 )

(C) 2018. The Author(s). Published under a Creative Commons Attribution Licence.
We used a data envelopment analysis (DEA) to examine the efficiency and performance of transport systems of landlocked African countries (LLACs). We conducted a comparative performance efficiency analysis of transfer transport systems for LLACs' corridors. Three different types of DEA models were proposed and used to measure the relative efficiencies of transit transport using a 6-year data set (2008-2013) of some selected LLACs. The results show that the average pure technical and scale efficiency scores are $90.89 \%$ and $37.13 \%$, respectively. Two units $(13.33 \%)$ are technically efficient (technical and scale efficiency) while four units $(26.66 \%)$ are only purely technically efficient over the observed period. Swaziland was the most efficient corridor while the Central African Republic corridor was the least efficient throughout the monitored years. The results indicate the relevance of minimising trade costs to stimulate landlocked countries' exports.

\section{Significance:}

- This study is the first efficiency study on transit transport corridors of landlocked African countries.

- DEA is an effective analytical tool for corridors evaluation and can help decision-makers in finding practical solutions.

- Some corridors are efficient, which means that other landlocked countries can learn from these efficient corridors to improve their corridor services.

\section{Introduction}

Landlocked can be defined as 'the geographical situation of a country without direct access to the sea'. Because of the lack of direct access to the sea, landlocked African countries (LLACs) are marginalised from major transportation and services (e.g. logistics, information technology) networks. In addition to their long distance to world markets, uncooperative transit procedures (e.g. red tape) and poor infrastructure contribute to an increase in transport and trade costs, thereby reducing international trade and subsequently economic growth. ${ }^{2}$

Landlocked countries in Africa (Figure 1) are entirely dependent on their neighbour's transit infrastructure and administrative procedures to transport their goods to and from the ports. In many cases, transit neighbours of LLACs are also developing countries, often with similar economic structure and beset by similar scarcities of resources. Their fragile infrastructures, complex customs and administrative setup result in higher transaction costs of trade through the transit country, which restricts the capacity of LLACs to compete favourably in international markets. ${ }^{3}$ Companies in LLACs are struggling to get their goods to their destination without major delays, which increases their operating costs. It is reported that landlocked developing countries (LLDCs) have to endure, on average, about $50 \%$ higher international transport costs than their neighbouring transit/coastal countries. ${ }^{4}$ Many authors have shown that these high barriers to trade are not only a result of geographical location but also have institutional and physical factors. ${ }^{5}$

Problems encountered by landlocked countries in trade through other territories are numerous, and range from long distances from the sea to insufficient transport services and infrastructure, and inefficient institutional and operational transit networks. ${ }^{6}$ Over the past 10 years, various studies on transit economics ${ }^{7-9}$ have shown that the undependability of the transit logistics system is the greatest barrier faced by manufacturers in LLDCs. A recent study by the World Bank shows that while greater attention has been given to road infrastructure and administration of international road services, accessibility of markets is still based on rules favouring and protecting national haulers. ${ }^{10}$ The costs of being landlocked are extensively documented by the United Nations. ${ }^{11}$ Figure 2 and Table 1 exemplarily show a comparative analysis of a recent survey.

Despite the progress achieved on many fronts regarding LLDCs, scepticism remains as to the possibility of finding effective and comprehensive solutions to the transport challenges. ${ }^{8}$ In order to increase the competitiveness of landlocked countries and improve the efficiencies of the corridors, transit agreements that aim at diminishing these constraints need to be taken into account, especially regarding international trade facilitation, multimodal transport, information systems and transport security. The contribution of efficient corridors to the economic development of a country is undeniable. It is important to analyse the efficiency of transit corridors to be able to improve the service of these corridors.

The evaluation of efficiency is imperative to stay competitive and flourish in a global business environment. Efficiency has been analysed from various perspectives using different techniques. ${ }^{12}$ However, analysis of these efficiencies is multi-dimensional and requires the support of multi-criteria decision-making tools. ${ }^{13}$ Therefore, the management of international trade corridors requires development of appropriate decision-support models that will provide adequate support for strategic decisions. One of the most promising decision-support models for evaluating corridor performance efficiency is the non-parametric method called data envelopment analysis (DEA). 


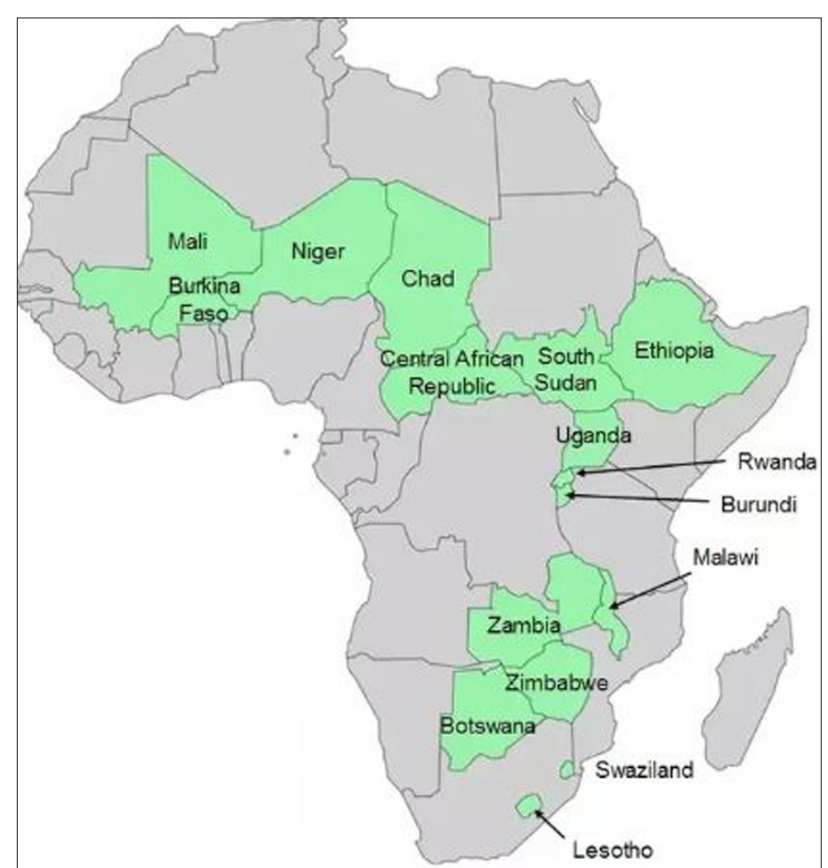

Figure 1: Landlocked African countries. The Republic of South Sudan was not included in the analysis as data were not available.

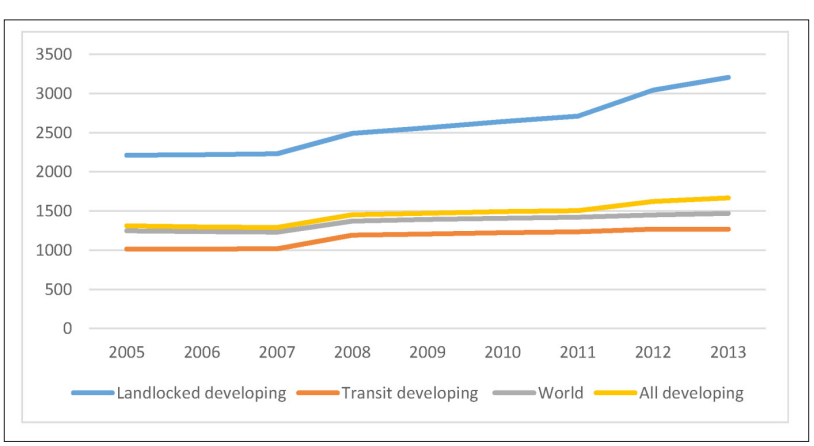

Figure 2: Cost to export (USD per container), modified according to the UN-OHRLLS ${ }^{11}$ indicators.

This analysis has been applied in assessing the performances of various kinds of entities engaged in many activities of varying contexts ${ }^{14}$ and to compare the efficiencies of non-profit and profit organisations ${ }^{15}$. In the transportation industry, DEA has been implemented in the following areas: ports ${ }^{16}$, railways ${ }^{17}$, airlines ${ }^{18}$ and urban transit ${ }^{19}$. To date, DEA has not been applied in the transit transport of LLACs. It should be noted that the African transfer transport system is one of the major focal areas towards sustainable transport development for landlocked export products through transit countries.

\section{Problem statement}

Nearly a third of African countries are landlocked. However, there is a dearth of literature on the efficiency and performance of their transport systems in terms of inland transport infrastructure, customs and trade facilitation, cross-border cooperation, port and terminal handling in transit countries. The objectives of this study were to: (1) evaluate the efficiencies of the transit corridors of LLACs in order to identify sources of inefficiencies and (2) determine the best performing corridor through efficiency ranking. To achieve these objectives, the DEA method was applied using data available from the United Nations.

The contributions of this study are twofold. Firstly, the application of DEA in the transit transport of LLACs is non-existent in the literature. To the best of our knowledge, this study was the first to apply DEA in this context. Secondly, the results provide guidelines to policymakers and regional organisations in LLACs who are dealing with the transport sector in framing strategies that will promote transact trade efficiently.

\section{Literature review}

The two most important concepts in performance measurements are productivity and efficiency. ${ }^{20}$ There are two classifications of productivity measurement: parametric frontier approach and non-parametric frontier approach. ${ }^{21}$ Regarding the parametric frontier approach, Wang et al. ${ }^{22}$ state that 'the productivity frontier is estimated in a particular functional form with constant parameters'. They further note that 'the non-parametric frontier approach assumes no particular functional form for the frontier'. The non-parametric frontier technique that is used most is DEA. ${ }^{14}$

However, in some studies, a combination of DEA and parametric frontiers has been used to identify the differences among the efficiency indexes obtained from the two approaches. ${ }^{23}$ The findings are very similar, which supports the application of DEA. This verification can be seen in many studies carried out in several countries, such as Norway ${ }^{24}$, Turkey ${ }^{25}$ and the USA ${ }^{26}$.

In recent years, many studies have attempted to evaluate transport efficiency using DEA. Among these include a study by García Sánchez ${ }^{27}$ who used DEA to compare the efficiency of Spain's public bus transport system. The paper focused on the estimation of technical and scale efficiency. In another study by Petrović et al. ${ }^{28}$, DEA was used to investigate multi-year rail freight transportation efficiency of some selected European nations. Their results provided each country's efficiency scores and suggested areas of improvement together with a discussion on factors that 'drive' efficiency. Savolainen and Hilmola ${ }^{29}$ applied DEA to estimate the relative technical efficiency of three European transportation systems - air, rail and maritime.

The application of DEA to the port industry is fundamentally not new. DEA has been successfully applied to analyse container terminals at seaports. The research papers in this field can be classified into two main groups according to the data analysed: cross-sectional data and panel data.

The DEA approach was applied by Barros ${ }^{30}$ using cross-sectional data to analyse the allocative and technical efficiency of five Portuguese ports from 1999 to 2000. The key objective of that study was to examine how port regulatory processes impact on port productivity. The study concluded that the incentive regulation for improving productive efficiency was not helping to achieve its aims and made policy recommendations to enforce efficiency. In another study, Martinez-Budria et al. ${ }^{31}$ divided 26 Spanish ports into three groups - high complexity ports, medium

Table 1: $\quad$ Average number of days (TT) and costs (TC, USD per TEU) to export by year, 2008-2013 (modified based on UN-OHRLLS11 indicators)

\begin{tabular}{|c|c|c|c|c|c|c|c|c|c|c|c|c|}
\hline & \multicolumn{2}{|c|}{2008} & \multicolumn{2}{|c|}{2009} & \multicolumn{2}{|c|}{2010} & \multicolumn{2}{|c|}{2011} & \multicolumn{2}{|c|}{2012} & \multicolumn{2}{|c|}{2013} \\
\hline & TT & TC & TT & TC & TT & TC & TT & TC & TT & TC & TT & TC \\
\hline Landlocked developing countries & 48 & 2490 & 46 & 2560 & 44 & 2640 & 43 & 2710 & 42 & 3040 & 42 & 3204 \\
\hline Transit developing countries & 25 & 1190 & 24 & 1205 & 23 & 1221 & 23 & 1235 & 23 & 1268 & 22 & 1268 \\
\hline All developing countries & 28 & 1370 & 27 & 1392 & 26 & 1405 & 26 & 1420 & 26 & 1450 & 26 & 1468 \\
\hline World & 25 & 1452 & 24 & 1470 & 23 & 1493 & 23 & 1503 & 23 & 1620 & 22 & 1667 \\
\hline
\end{tabular}


complexity ports and low complexity ports - and assessed their efficiencies using the DEA CCR (Charnes, Cooper and Rhodes) model and the DEA BCC (Banker, Charnes and Cooper) model. ${ }^{32}$ They found that high complexity ports were associated with high efficiency, while the other two groups had a random mix of medium and low efficiency.

Using DEA windows analysis, Cullinane et al..$^{33}$ combined panel data and cross-sectional data to evaluate the efficiency of the world's major container seaports and showed that the cross-sectional data did not offer a comprehensive view of the ports' performances. The panel data indicated a dissimilarity between the absolute performance of the port and its relative performance in contrast to others over the same period. Min and Park ${ }^{34}$ and Pjevcevic et al. ${ }^{35}$ proposed DEA window analysis to evaluate the efficiencies of ports and container terminals over a period of 4 years. The DEA window analysis applied helped to observe the changes in the ports and terminal efficiencies. Cullinane and Wang ${ }^{36}$ used DEA to examine the efficiencies of 69 Europe container terminals with an annual throughput of over 10000 TEU (twenty-foot equivalent unit). They argued that there were significant inefficiencies for most of the terminals. It was also evident that the average efficiency of container terminals in different geographical locations differed, either to a large or to a small extent.

In Africa, there is a fairly large body of literature in regard to 'landlockedness' and related issues such as port efficiencies ${ }^{37}$ and hinterland relationships ${ }^{8}$. Some of this literature is in the form of reports by government agencies and regional or international organisations (e.g. the United Nations Office of the High Representative for the Least Developed Countries, Landlocked Developing Countries and Small Island Developing States or UN-OHRLLS ${ }^{11}$ ). In 1982, the United Nations Convention on the Law of the Sea announced the 'Right of Access of Landlocked States to and from the Sea and Freedom of Transit'. It stated that landlocked countries may have the admittance to and from the sea, and the freedom of transit through transit countries zone by all means of transport without any restriction. ${ }^{38}$ However, in practice, the application of this elementary rule undergoes various operational difficulties, resulting in long transit times and high transport costs. ${ }^{39}$ More recently, higher costs and longer transit times have also been seen by the World Bank as the causes for the lack of competitiveness of traders from LLACs. ${ }^{3}$

Over the past decade, under the 'Almaty Programme of Action' initiated in 2003, new research and comprehensive studies have brought fresh knowledge on the transfer transport systems of landlocked countries. Among these is the study of Djankov et al. ${ }^{2}$ who offered a clear diagnostic of the current situation of LLDCs. They took a closer look at the dependence of landlocked countries on export goods and measured the impact of transit policy on transport costs and services. They further pointed out specific problems that affect operation, improvement and maintenance of transit transport infrastructure in LLACs and discussed promising options for the more efficient mutual use of infrastructure in landlocked and transit countries.

Although the problem of enclosure has been discussed in studies in Africa, there is sparse literature on the transport system of LLACs especially with regard to inland transport infrastructure, customs and trade facilitation, port and terminal handling. A comparative analysis of the efficiency of transit transport corridors of LLACs has not yet been undertaken. A few studies have described briefly the specific problem faced by LLACs in their respective transit corridors. ${ }^{6,7}$ Empirical analysis in this area is still insufficient and real data need to be collected for analysis. In this study we focused on evaluation of the performance of corridors using DEA.

\section{Research methodology}

\section{$C R S$ and VRS DEA techniques}

Data envelopment analysis is a linear programming method that uses multiple inputs and outputs to evaluate the relative efficiency of homogeneous units (termed decision-making units or DMUs)..$^{14}$ DEA aids in the computation of the efficiency as a ratio of the weighted sum of outputs to the weighted sum of inputs. As it is impossible to determine the 'absolute efficiency' that is evaluated based on the ideational datum point, the degree of efficiency is measured by comparing the units with a reference set that has identical input and output structure. ${ }^{40}$

Considering a set of input and output variables, DEA provides a unified performance efficiency measurement (efficiency score) for each DMU. This measurement is completed by developing an empirically based 'best-practice' or efficient frontier as a result of an identified set of efficient DMUs (on the frontier) and inefficient DMUs (not on the frontier). According to Wu and Liang ${ }^{41}$, inputs are considered as resources used by a DMU while outputs are products produced and/or performance outcomes of the DMU.

Reflecting the type of frontier (i.e. envelopment surface), there are two forms of DEA models: CRS and VRS models. The CRS model was proposed by Charnes et al. ${ }^{42}$ and the key concept of this model is to assume constant returns to scale (hence the name CRS, or alternatively CCR after Charnes, Cooper and Rhodes). The CRS assumption is suitable when all DMUs are operating at an optimal scale. Limited competition, financial difficulties, etc., may cause a DMU to not operate at optimal scale. ${ }^{43}$ Banker et al. ${ }^{32}$ proposed an extension of the CRS-DEA model to account for variable returns to scale (hence the name VRS, or alternatively BCC for Banker, Charnes and Cooper).

Using CRS specifications will result in measures of technical efficiency which are confounded by scale efficiency when not all DMUs are operating at the optimal scale. The use of VRS specifications will allow the computation of technical efficiency devoid of these scale efficiency effects. The CRS technical efficiency measure is decomposed into 'pure' technical efficiency (VRS efficiency) and scale efficiency as in Equation 127:

Scale efficiency $(S E)=\frac{\text { CRS efficiency }}{V R S \text { efficiency }}$

Equation 1

The DEA model can be used either as input or output orientation. On one hand, 'input-oriented technical efficiency measures' maintain the output constant while the proportion of potential decrease in the input usage is investigated. On the other hand, 'output-oriented technical efficiency measures' prevent any change to input (fixed input) while the proportional expansion in output quantities is considered..$^{36}$ Under CRS, the DEA results are similar in both input and output orientation, whereas under VRS, the two results are not generally equivalent. Because it was considered challenging to capture and ensure the stability of transport conditions, both CRS and VRS models were used in this work. Also, we decided to use an input-oriented model to measure CRS and VRS efficiency because the aim was to determine the possibility of input reduction by maintaining the same level of output.

\section{Benefits and limitations of DEA}

When applying a DEA model effectively and wisely, there are various advantages; however, some conditions need to be taken into account. ${ }^{15}$ DEA permits efficiency evaluation over time and can deal with multiple inputs and outputs with different units. Also, DMUs are directly compared against a peer or combination of peers. Furthermore, in DEA, no assumption of a functional form relating inputs to outputs is required. Nevertheless, some limitations become inevitable with a DEA model.

Firstly, DEA leads to results that are especially sensitive to measurement error and only assesses efficiency relative to the best practice within the specific sample. Therefore, it cannot be used to compare scores between two different studies. In addition, DEA estimates the 'relative' efficiency of a DMU; it converges very gradually to 'absolute' efficiency. DEA clarifies the significance of a DMU compared with its peers regardless of a 'theoretical maximum'. Finally, all efficient units in DEA are assigned the same score (1.00), therefore their further ranking is not possible.

In order to increase the effectiveness of DEA and correct these limitations, unnecessary imputations of missing data influencing the corridor sample size were nullified. To determine the best performing corridor (i.e. to rank the efficient corridor), we relied on the modified DEA model proposed by Andersen and Petersen ${ }^{44}$. This model allows the ranking of efficient units, through the calculation of so-called 'super-efficiency scores'. Andersen 
and Petersen ${ }^{44}$ have pointed out that the attribution of a score greater than 1.000 to the efficient units by relaxing the constraint that bounds the score of the evaluated unit $k$, explicitly the primary problem of unit $k$, can be defined as in M1 and M2 below.

The DEA model M1 is mathematically expressed as ${ }^{14,15}$ :

$M 1 \begin{cases}\operatorname{Max}_{k}(u, v)=\frac{\sum_{r=1}^{s} u_{r} y_{r k}}{\sum_{i=1}^{m} v_{i} x_{i k}} \text { for all } k=1,2, \ldots, n & \text { Equation 2 } \\ \text { subject to } & \\ \frac{\sum_{r=1}^{s} u_{r} y_{r j}}{\sum_{i=1}^{m} v_{i} x_{i j}} \leq 1, j=1,2, \ldots, n & \text { Equation 3 } \\ u_{r} \geq 0, r=1,2, \ldots, s & \\ v_{r} \geq 0, i=1,2, \ldots, m & \text { Equation 4 }\end{cases}$

where:

- $\quad h_{k}$ is the relative efficiency of $k$-th DMU;

- $\quad y_{r j}$ is the amount of output $r$ generated by DMU $j$;

- $\quad x_{i j}$ is the amount of input $i$ utilised by DMU $j$;

- $\quad n$ is the number of DMUs;

- $\quad m$ is the number of inputs;

- $\quad s$ is the number of outputs;

- $\quad u_{r}$ is the weight assigned to output $r$;

- $\quad v_{i}$ is the weight assigned to input $i$.

Model M1 is resolved $n$ times to measure the relative efficiency of each DMU. Mathematically, the non-negative constraints in Equations 4 and 5 are not sufficient for the fractional Equation 3 to have a value greater than zero. On this basis, all weights for inputs and outputs assumed nonzero values. As the efficiency of $k$-th DMU is maximised by resolving the expressions in Equations 2-5, it can be seen that $h_{k}$ takes values from 0 to 1 . If the value for $h_{k}$ is 1 , then the $k$-th DMU is efficient relative to other DMUs. Otherwise, the value of $h_{k}$ shows the inefficiency of $k$-th DMU. However, if the value of $h_{k}$ tends to 1 , it can be considered as 'less efficient'.

This problem can be addressed using fractional linear programming model M1, known as 'CCR ratio model', which can be mitigated using transformations to the linear programming model M2. The DEA model M2 is proposed in the following forms:

$M 2\left\{\begin{array}{lr}\operatorname{Max}_{k}(\mu, v)=\sum_{r=1}^{s} \mu_{r} y_{r k} \text { for all } k=1,2, \ldots, n & \text { Equation 6 } \\ \text { subject to } & \text { Equation 7 } \\ \sum_{i=1}^{m} v_{i} x_{i k}=1 & \\ \sum_{r=1}^{s} \mu_{r} y_{r j}-\sum_{i=1}^{m} v_{i} x_{i j} \leq 0, j=1,2, \ldots, n & \text { Equation 8 } \\ \mu_{r} \geq 0, r=1,2, \ldots, s & \text { Equation 9 } \\ v_{i} \geq 0, i=1,2, \ldots, m & \text { Equation 10 }\end{array}\right.$ where:

- $\quad y_{r j}$ is the amount of output $r$ generated by DMU $j$;

- $\quad x_{i j}$ is the amount of input $i$ to unit $j$;

- $\quad h_{k}$ is the relative efficiency of the unit $k$;

- $\quad n$ is the number of DMUs under investigation;

- $\quad m$ is the number of inputs;

- $\quad s$ is the number of outputs;

- $\quad \mu_{r}$ is the weight coefficient of output $r$;

- $\quad v_{i}$ is the weight coefficient of input $i$.

The $k$-th DMU is relatively efficient if the value of $h_{k}$ in the objective function is equal to 1 , and DMUk is relatively inefficient if $h_{k}$ is less than 1. In that case, the value of $h_{k}$ indicates the percentage by which DMU should reduce its inputs. DMUk is considered to be fully efficient only if the other DMU values do not indicate that any of its inputs or outputs can be improved without impairing any other input or output.

The super-efficiency model defined above was used in this paper to rank the efficient corridors and determine the best performing ones. For VRS, CRS and super-efficiency, we used Efficiency Measurement System (EMS) - software that computes efficiency scores. ${ }^{45} \mathrm{~A}$ detailed explanation of these DEA models is in the supplementary material.

\section{Description of the data}

We employed three inputs and one output in the DEA efficiency computations. For inputs we selected: transaction costs (USD per TEU), transaction time (days) and the number of documents for exporting a standard shipment of goods by sea transport. For output, we used exports handled by each DMU (corridor) measured by TEU. Our choice of these variables is in line with those of Djankov et al. ${ }^{2}$ and are applied in this paper with minor modifications by considering a third factor (number of documents for export). A detailed explanation for the selection of these variables is in the supplementary material. Efficiency was calculated for 15 corridors over the period 2008-2013. Input data were obtained from the World Bank Doing Business database ${ }^{46}$ and the output data were sourced from the UN Comtrade database ${ }^{47}$. Supplementary table 1a and $1 \mathrm{~b}$ provides more details on the data sample.

Doing Business measures the time and cost (excluding tariffs) associated with exporting and importing a standardised cargo of goods by sea transport. For exporting goods, official procedures start from packing the goods into the container at the warehouse to their departure from the port of exit and includes processes at the inland border post. However, the time and cost for sea transport are excluded. All the necessary documents required from the trader to export the goods across the border are also recorded.

To make the data comparable across economies and to avoid special cases, several assumptions about the business and the traded goods were used by the Doing Business data survey. ${ }^{3}$ All exporters (100\% domestically owned) had at least 60 employees and were located in the economy's largest business city. The goods traded were one of the economy's leading export products. The goods traded travelled in a dry cargo, 20-foot full container load that weighed 10 tons and was priced at USD20 000 . Each year, more than $10 \%$ of gross revenue must have been from international trade. Additionally, the exporter should not have operated in an export processing area or industrial zone for which special export privileges existed. Furthermore, the goods traded did not constitute hazardous or military items, nor did they require refrigeration or any other special environmental safety standards other than internationally accepted standards. Our first intention was to evaluate all 16 main transit corridors servicing landlocked countries in Africa. However, South Sudan was excluded from the analysis because of the unavailability of data. 


\section{Results and discussions}

The results obtained from DEA CRS and VRS models are shown in Table 2. These results contain VRS efficiency, scale efficiency and CRS efficiency scores denoted by Evrs, Ese and Ecrs, respectively. The DEA super-efficiency model results are also listed in Table 3.

The results on DEA CRS efficiency indicate that only Botswana's and Zambia's corridors were technically efficient throughout the whole period. Yet some corridors were efficient in the case of DEA with VRS. Swaziland's, Botswana's and Zambia's corridors were efficient based on the VRS model in the observed period while Lesotho's, Malawi's and Mali's were relatively efficient over the period. Furthermore, the average index of VRS efficiency was better than the average scores for CRS efficiency.

A corridor may be considered efficient in terms of VRS and inefficient in CRS terms. This distinction is as a result of scale inefficiency.

Table 2: Efficiency scores ('pure' technical - Evrs, scale - Ese and technical - Ecrs) for 15 corridors, 2008-2013

\begin{tabular}{|c|c|c|c|c|c|c|c|c|c|c|c|c|c|c|c|c|c|c|}
\hline \multirow[t]{2}{*}{ Corridor } & \multicolumn{3}{|c|}{2008} & \multicolumn{3}{|c|}{2009} & \multicolumn{3}{|c|}{2010} & \multicolumn{3}{|c|}{2011} & \multicolumn{3}{|c|}{2012} & \multicolumn{3}{|c|}{2013} \\
\hline & Ecrs & Evrs & Ese & Ecrs & Evrs & Ese & Ecrs & Evrs & Ese & Ecrs & Evrs & Ese & Ecrs & Evrs & Ese & Ecrs & Evrs & Ese \\
\hline Botswana & 1.00 & 1.00 & 1.00 & 1.00 & 1.00 & 1.00 & 1.00 & 1.00 & 1.00 & 1.00 & 1.00 & 1.00 & 1.00 & 1.00 & 1.00 & 1.00 & 1.00 & 1.00 \\
\hline Burkina Faso & 0.09 & 0.79 & 0.11 & 0.22 & 0.79 & 0.28 & 0.22 & 0.80 & 0.28 & 0.45 & 0.77 & 0.58 & 0.45 & 0.80 & 0.57 & 0.46 & 0.86 & 0.53 \\
\hline Burundi & 0.02 & 0.68 & 0.03 & 0.02 & 0.67 & 0.03 & 0.02 & 0.70 & 0.03 & 0.02 & 0.67 & 0.03 & 0.03 & 0.70 & 0.05 & 0.02 & 0.71 & 0.03 \\
\hline $\begin{array}{l}\text { Central African } \\
\text { Republic }\end{array}$ & 0.02 & 0.75 & 0.02 & 0.02 & 0.75 & 0.02 & 0.01 & 0.67 & 0.02 & 0.01 & 0.67 & 0.02 & 0.01 & 0.67 & 0.02 & 0.00 & 0.67 & 0.01 \\
\hline Chad & 0.75 & 0.86 & 0.88 & 0.61 & 0.86 & 0.71 & 0.47 & 0.86 & 0.55 & 0.51 & 0.86 & 0.60 & 0.42 & 0.86 & 0.49 & 0.42 & 0.86 & 0.50 \\
\hline Ethiopia & 0.34 & 0.97 & 0.35 & 0.42 & 0.84 & 0.50 & 0.39 & 0.91 & 0.42 & 0.56 & 0.92 & 0.62 & 0.62 & 0.97 & 0.64 & 0.69 & 0.96 & 0.71 \\
\hline Lesotho & 0.06 & 1.00 & 0.06 & 0.25 & 1.00 & 0.25 & 0.15 & 0.99 & 0.16 & 0.33 & 1.00 & 0.33 & 0.26 & 0.98 & 0.27 & 0.23 & 1.00 & 0.23 \\
\hline Malawi & 0.22 & 1.00 & 0.22 & 0.44 & 1.00 & 0.44 & 0.23 & 1.00 & 0.23 & 0.39 & 1.00 & 0.39 & 0.24 & 0.78 & 0.30 & 0.23 & 0.81 & 0.28 \\
\hline Mali & 0.38 & 0.97 & 0.39 & 0.55 & 0.98 & 0.57 & 0.43 & 1.00 & 0.43 & 0.51 & 1.00 & 0.51 & 0.50 & 1.00 & 0.50 & 0.47 & 1.00 & 0.47 \\
\hline Niger & 0.17 & 0.85 & 0.20 & 0.13 & 0.75 & 0.17 & 0.06 & 0.75 & 0.08 & 0.14 & 0.75 & 0.18 & 0.17 & 0.75 & 0.22 & 0.16 & 0.75 & 0.21 \\
\hline Rwanda & 0.05 & 0.86 & 0.05 & 0.06 & 0.75 & 0.08 & 0.04 & 0.79 & 0.05 & 0.07 & 0.86 & 0.09 & 0.09 & 0.92 & 0.10 & 0.08 & 0.87 & 0.09 \\
\hline Swaziland & 0.53 & 1.00 & 0.53 & 0.63 & 1.00 & 0.63 & 0.47 & 1.00 & 0.47 & 0.51 & 1.00 & 0.51 & 0.50 & 1.00 & 0.50 & 0.29 & 1.00 & 0.29 \\
\hline Uganda & 0.36 & 0.98 & 0.37 & 0.40 & 0.87 & 0.46 & 0.31 & 0.88 & 0.35 & 0.37 & 0.86 & 0.43 & 0.38 & 0.87 & 0.44 & 0.33 & 0.86 & 0.39 \\
\hline Zambia & 1.00 & 1.00 & 1.00 & 1.00 & 1.00 & 1.00 & 1.00 & 1.00 & 1.00 & 1.00 & 1.00 & 1.00 & 1.00 & 1.00 & 1.00 & 1.00 & 1.00 & 1.00 \\
\hline Zimbabwe & 0.31 & 0.93 & 0.34 & 0.53 & 0.86 & 0.61 & 0.44 & 0.86 & 0.52 & 0.44 & 0.86 & 0.51 & 0.52 & 0.86 & 0.61 & 0.45 & 0.86 & 0.53 \\
\hline Average efficiency & 0.35 & 0.91 & 0.37 & 0.42 & 0.87 & 0.45 & 0.35 & 0.88 & 0.37 & 0.42 & 0.88 & 0.45 & 0.41 & 0.88 & 0.45 & 0.39 & 0.88 & 0.42 \\
\hline Efficiency units & 2 & 5 & 2 & 2 & 5 & 2 & 2 & 5 & 2 & 2 & 5 & 2 & 2 & 4 & 2 & 2 & 5 & 2 \\
\hline Inefficiency units & 13 & 10 & 13 & 13 & 10 & 13 & 13 & 10 & 13 & 13 & 10 & 13 & 13 & 11 & 13 & 13 & 10 & 13 \\
\hline
\end{tabular}

Table 3: Data envelopment analysis super-efficiency scores in terms of variable returns to scale (VRS), 2008-2013

\begin{tabular}{|c|c|c|c|c|c|c|c|c|c|c|c|c|c|c|c|c|c|}
\hline \multicolumn{3}{|c|}{2008} & \multicolumn{3}{|c|}{2009} & \multicolumn{3}{|c|}{2010} & \multicolumn{3}{|c|}{2011} & \multicolumn{3}{|c|}{2012} & \multicolumn{3}{|c|}{2013} \\
\hline Rank & Corridor & VRS & Rank & Corridor & VRS & Rank & Corridor & VRS & Rank & Corridor & VRS & Rank & Corridor & VRS & Rank & Corridor & VRS \\
\hline 1 & SZ & 1.57 & 1 & SZ & 1.48 & 1 & SZ & 1.43 & 1 & SZ & 1.44 & 1 & SZ & 1.44 & 1 & BW & 1.49 \\
\hline 2 & BW & 1.56 & 2 & BW & 1.40 & 2 & BW & 1.29 & 2 & BW & 1.30 & 2 & BW & 1.29 & 2 & SZ & 1.44 \\
\hline 3 & MW & 1.17 & 3 & LS & 1.17 & 3 & MW & 1.14 & 3 & ML & 1.10 & 3 & ML & 1.07 & 3 & LS & 1.11 \\
\hline 4 & LS & 1.06 & 4 & MW & 1.01 & 4 & $\mathrm{ML}$ & 1.12 & 4 & LS & 1.04 & 4 & ZM & big & 4 & ML & 1.08 \\
\hline 5 & ZM & big & 5 & ZM & big & 5 & ZM & big & 5 & ZM & big & 5 & LS & 0.98 & 5 & ZM & big \\
\hline 6 & UG & 0.98 & 6 & $\mathrm{ML}$ & 0.98 & 6 & LS & 0.99 & 6 & MW & 1.00 & 6 & ET & 0.97 & 6 & ET & 0.96 \\
\hline 7 & ML & 0.97 & 7 & UG & 0.87 & 7 & ET & 0.91 & 7 & ET & 0.92 & 7 & RW & 0.92 & 7 & RW & 0.87 \\
\hline 8 & ET & 0.97 & 8 & TD & 0.86 & 8 & UG & 0.88 & 8 & TD & 0.86 & 8 & UG & 0.87 & 8 & $B F$ & 0.86 \\
\hline 9 & ZW & 0.93 & 9 & ZW & 0.86 & 9 & TD & 0.86 & 9 & RW & 0.86 & 9 & TD & 0.86 & 9 & TD & 0.86 \\
\hline 10 & RW & 0.86 & 10 & ET & 0.84 & 10 & ZW & 0.86 & 10 & UG & 0.86 & 10 & ZW & 0.86 & 10 & UG & 0.86 \\
\hline 11 & TD & 0.86 & 11 & BF & 0.79 & 11 & BF & 0.80 & 11 & ZW & 0.86 & 11 & BF & 0.80 & 11 & ZW & 0.86 \\
\hline 12 & $\mathrm{NE}$ & 0.85 & 12 & CF & 0.75 & 12 & RW & 0.79 & 12 & BF & 0.77 & 12 & MW & 0.78 & 12 & MW & 0.81 \\
\hline 13 & $B F$ & 0.79 & 13 & NE & 0.75 & 13 & NE & 0.75 & 13 & NE & 0.75 & 13 & NE & 0.75 & 13 & NE & 0.75 \\
\hline 14 & $\mathrm{CF}$ & 0.75 & 14 & RW & 0.75 & 14 & $\mathrm{Bl}$ & 0.70 & 14 & $\mathrm{Bl}$ & 0.67 & 14 & $\mathrm{BI}$ & 0.70 & 14 & $\mathrm{BI}$ & 0.71 \\
\hline 15 & BI & 0.68 & 15 & $\mathrm{BI}$ & 0.67 & 15 & $\mathrm{CF}$ & 0.67 & 15 & CF & 0.67 & 15 & CF & 0.67 & 15 & CF & 0.67 \\
\hline
\end{tabular}

BW, Botswana; BF, Burkina Faso; BI, Burundi; CF, Central African Republic; TD, Chad; ET, Ethiopia; LS, Lesotho; MW, Malawi; ML, Mali; NE, Niger; RW, Rwanda; SZ, Swaziland; UG, Uganda; ZM, Zambia; ZW, Zimbabwe 
A typical example here is Swaziland, which is observed to be VRS efficient over the whole period but inefficient in CRS and scale terms. Average efficiency scores were constant over the years, except for 2008. This exception may be seen as a need for new reform in transfer transport systems to facilitate exports. This also shows that implementing the DEA methods can produce good results and help LLACs in their strategic decisions.

The results on CRS efficiency indicate that Botswana and Zambia have the most successful corridors, but in terms of VRS more than two corridors showed efficiency (five countries in 2008 to 2011, four in 2012, and five in 2013). To determine the best performing corridor in the study, we applied super-efficiency in VRS terms. The results are depicted in Table 3. Super-efficiency DEA allows efficiency scores greater than 1.00 (i.e. bigger than 1.00 for input-oriented model) and enables the ranking of DMUs using the level of efficiency. Further discussion of the rankings is in relation to the results from applying super-efficiency.

Swaziland's corridor was ranked the highest (Rank 1) within the observed period, with the exception of 2013. Burundi's and the Central African Republic's corridors were in the last position in the observed period. The meaning of 'big' in Table 3 indicates that the DMU remains efficient under an arbitrary large increase in outputs. Nevertheless, if the same process is used in CRS terms, Zambia (2008, 2010 to 2012) and Botswana $(2009,2013)$ become the best exemplars. This change in results is because of the scale efficiency included in the CRS efficiency estimation (see Supplementary table 2).

The general findings suggest that there is no substantial difference in the estimation of super-efficiency throughout the observed period, as seen in the first five and the last five corridors (Table 3). This demonstrates that the performances of the corridors analysed were stable over the period. The explanations can be seen in the 'fixed' nature of inputs (no big difference for the number of documents and time spent over the years) and that transit transport services need more investment along with longer periods for their implementation. As suggested by Peter et al. ${ }^{48}$, decision-makers must put effort into selecting or encouraging the right type of infrastructure for the right period. Furthermore, the results show that there is a difference in the efficiency scores obtained between the intra-regional member and non-member states.

Apart from the efficiency scores, DEA records each inefficient unit (corridor) with its respective benchmark (efficiency reference set). The benchmark refers to an efficient corridor which is the closest corridor to the projection of an inefficient corridor on the frontier. For example, in 2013, DEA VRS indicated Botswana as a corresponding benchmark corridor for Niger (see Supplementary table 2c for more details). Further and broader analysis is required for the final decision on which country to benchmark against, which suggests that other criteria - such as demography, sociology or geography - ought to be considered.

In summary, within the 15 corridors considered in the study, only 5 were efficient. The results confirm that landlocked economies in Africa have the most challenging environments with regard to business regulations. ${ }^{7,10}$ Indeed, of the 10 most difficult places in the world to carry out business, a disproportionate number are LLACs: the Central African Republic, Burundi, Chad and Niger. ${ }^{49}$ In a recent study, the UNOHRLLS revealed that the transport costs of LLDCs were $45 \%$ higher than those of representative coastal countries. According to Arvis et al. ${ }^{6}$, the basic import and export costs of LLDCs were nearly twice those of their transit neighbours. These findings prove that there is a great need for better African trade integration. ${ }^{50}$

Previous studies have predominantly focused on the impact on economies of being landlocked in comparison to coastal ${ }^{8}$, without explicitly identifying the relative efficiency of the transfer transport system of those countries. Thus, this paper contributes towards filling this gap. Our results show some efficient corridors, e.g. Botswana and Swaziland, indicating that some landlocked countries are making progress and that LLACs can learn from one another. The findings prove that the implementation of DEA can be beneficial and useful for the evaluation of the performance of LLACs. A better understanding of the efficiency of the transit transport corridors of LLACs may lead to better decision-making for trade facilitation measures and was the core focus of this paper. We have demonstrated the applicability of DEA in this strategic decision-making.

\section{Conclusions and recommendations}

This study was primarily done to evaluate the efficiency of the main transit corridors linking landlocked countries and sea ports in Africa for the years 2008-2013. We further determined the sources of inefficiencies (higher transaction costs/time) and make proposals for their improvement. Our results have important implications for LLDCs seeking to expand their exports by helping decision-makers to find practical solutions that will promote trade efficiently.

The results reveal that 10 of the 15 corridors were relatively inefficient (Swaziland being the most efficient). The top five corridors are located in southern Africa and the bottom five are in Central and West Africa. This suggests that trade facilitation measures and port performance (such as multimodal transports, terminals, reformed policies, procedures and regulations) are better implemented in the south than in the rest of the continent. The average performance of the 15 corridors examined was also stable over time, pointing to the fact that the need for regional transit reform is felt urgently. For the more efficient use of transit transport infrastructures in both the transit and landlocked countries, the removal of physical and non-physical barriers to trade (e.g. bureaucracy) remains a major challenge. Simplification and harmonisation of customs and administrative documentation, new technologies, trade facilitation and procedures which can be attained with modest investment can achieve immediate benefits in terms of improving transit times and reducing transit transport costs.

Efficiency is the key performance indicator in transport. The DEA method can aid in the evaluation of efficiency for cross-country comparisons of transfer transport systems in LLACs. DEA super-efficiency allows the ranking of efficient corridors and the determination of the bestperforming corridors. The estimated efficiencies are relative and depend on the selection of corridors. We want to emphasise that additional inputs and outputs - for example, indicators on sector investments (for input) and revenues (output) - can improve the findings and can be the subject of future research.

\section{Acknowledgements}

We acknowledge Lucienne and Pierre Fanou for their financial support and Dr Simonov Kusi-Sarpong and Dr Henry Musoke Semakula who provided critical comments and important suggestions.

\section{Authors' contributions}

E.H.F. was responsible for collecting information, computing and interpreting the data, and writing the manuscript. X.W. was the supervisor of this research project and provided advice on the data analysis and manuscript structure.

\section{References}

1. Bayeh $\mathrm{E}$. The rights of land-locked states under the international law: The role of bilateral/multilateral agreements. Soc Sci. 2015;4(2):27-30. http://dx.doi. org/10.11648/j.ss.20150402.12

2. Djankov S, Freund C, Pham CS. Trading on time. Rev Econ Stat. 2010;92:166173. http://dx.doi.org/10.1162/rest.2009.11498

3. The World Bank. Trading across borders. In: Doing Business 2013: Smarter regulations for small and medium-size enterprises. Washington DC: World Bank Group; 2013. p. 123-124. http://dx.doi.org/10.1596/978-0-82139615-5

4. United Nations. Transport and trade facilitation series no. 4. In: The way to the ocean: Transit corridors servicing the trade of landlocked developing countries. New York and Geneva: United Nations; 2013. p. 1-27.

5. Foroutan F, Pritchett L. Intra-sub-Saharan African trade: Is it too little? Afr Econ. 1993;2(1):74-105. https://doi.org/10.1093/oxfordjournals.jae. a 036775

6. Arvis JF, Raballand G, Marteau JF. The cost of being landlocked: Logistics costs and supply chain reliability. World Bank Policy Research Working Paper 4258. Washington DC: World Bank Group; 2007. p. 1-81. http://dx.doi. org/10.1596/1813-9450-4258 
7. Venables AJ. Infrastructure, geographical disadvantage, and transport. World Bank Policy Research Working Paper 2257. Washington DC: World Bank Group; 1999. p. 1-37.

8. Faye ML, McArthur JW, Sachs JD, Snow T. The challenges facing landlocked developing countries. J Hum Dev. 2004;5(1):31-68. http://dx.doi.org/10.108 0/14649880310001660201

9. Collier P. The bottom billion: Why the poorest countries are failing and what can be done about it. New York. Oxford University Press; 2007.

10. Kunaka C, Tanase V, Latrille P, Krausz P. Quantitative analysis of road transport agreements (QuARTA). Washington DC: The World Bank; 2013.

11. United Nations Office of the High Representative for the Least Developed Countries, Landlocked Developing Countries and Small Island Developing States (UN-OHRLLS). The development economics of landlockedness: Understanding the development costs of being landlocked. New York: UNOHRLLS; 2013.

12. Du Plessis W. Energy efficiency and the law : A multidisciplinary approach. S Afr J Sci. 2015;111(1/2), Art. \#2013-0302, 8 pages. http://dx.doi. org/10.17159/sajs.2015/20130302

13. Wit M De, Crookes DJ. Improved decision-making on irrigation farming in arid zones using a system dynamics model. S Afr J Sci. 2013;109(11/12), Art. \#2013-0191, 8 pages. http://dx.doi.org/10.1590/sajs.2013/20130191

14. Cooper W, Seiford LM, Zhu J. Data envelopment analysis: History, models, and interpretations. J Econometrics. 2011;46:1-39. http://dx.doi.org/978-14419-6150

15. Cooper WW, Seiford LM, Tone K. Introduction to data envelopment analysis and its uses: With DEA-solver software and references. New York: Springer; 2006. http://dx.doi.org/10.1007/0-387-29122-9

16. Liu C-C. Evaluating the operational efficiency of major ports in the Asia-Pacific region using data envelopment analysis. Appl Econ. 2008;40(13):17371743. http://dx.doi.org/10.1080/00036840600905126

17. Hilmola 0-P. European railway freight transportation and adaptation to demand decline: Efficiency and partial productivity analysis from period of 1980-2003. Int J Product Perform Manag. 2007;56(3):205-225. http:// dx.doi.org/10.1108/17410400710731428

18. Ha H-K, Yoshida Y, Zhang. A. Comparative analysis of efficiency for major northeast Asia airports. Transp J. 2010;49(4):9-23.

19. Boame AK. The technical efficiency of Canadian urban transit systems. Transp Res Part E. 2004;40:401-416. http://dx.doi.org/10.1016/j.tre.2003.09.002

20. Isaksson K, Huge-Brodin M. Understanding efficiencies behind logistics service providers' green offerings. Manag Res Rev. 2015;36(3):216-238. http://dx.doi.org/10.1108/01409171311306382

21. Graham DJ. Productivity and efficiency in urban railways: Parametric and nonparametric estimates. Transp Res Part E Logist Transp Rev. 2008;44(1):8499. http://dx.doi.org/10.1016/j.tre.2006.04.001

22. Wang T, Song D, Cullinane K. Container port production efficiency: A comparative study of DEA and FDH approaches. J East Asian Soc Transp Stud. 2003;5:698-713.

23. Obeng K. Bus transit technical efficiency using latent class stochastic indirect production frontier. Appl Econ. 2013;45(28):3933-3942. http://dx.doi.org/10 1080/00036846.2012.736946

24. Odeck J, Alkadi A. Evaluating efficiency in the Norwegian bus industry using data envelopment analysis. Transportation (Amst). 2001;28(3):211-232. https://doi.org/10.1080/03081060108717663

25. Kasap Y. The effect of work accidents on the efficiency of production in the coal sector. S Afr J Sci. 2011;107(5/6):77-85. http://dx.doi.org/10.4102/ sajs.v107i5/6.513

26. Karlaftis MG. A DEA approach for evaluating the efficiency and effectiveness of urban transit systems. Eur J Oper Res. 2004;152(2):354-364. https://doi. org/10.1016/S0377-2217(03)00029-8

27. García Sánchez IM. Technical and scale efficiency in Spanish urban transport: Estimating with data envelopment analysis. Adv Oper Res. 2009;2009, Art. \#721279, 15 pages. http://dx.doi.org/10.1155/2009/721279

28. Petrović M, Pejčić-Tarle S, Vujičić M, Bojković N. A DEA based approach for cross-country evaluation of rail freight transport: Possibilities and limitations. Belgrade: University of Belgrade; 2012.
29. Savolainen VV, Hilmola OP. The relative technical efficiency of European transportation systems concerning air transport and railways. Int $J$ Bus Perform Manag. 2009;11(1-2):19-42. http://dx.doi.org/10.1504/ ijbpm.2009.023799

30. Barros CP. The measurement of efficiency of Portuguese sea port authorites with DEA. Int J Transp Econ. 2003;30(3):335-354

31. Martinez-Budria E, Diaz-Armas R, Navarro-lbanez M, Ravelo-Mesa T. A study of the efficiency of Spanish port authorities using data envelopment analysis. Int J Transp Econ. 1999;26: 237-253.

32. Banker RD, Charnes A, Cooper WW. Some models for estimating technica and scale inefficiencies in data envelopment analysis. Manage Sci. 1984;30(9):1078-1092. http://dx.doi.org/10.1287/mnsc.30.9.1078

33. Cullinane K, Song D-W, Ji P, Wang T-F. An application of DEA windows analysis to container port production efficiency. Rev Netw Econ. 2004;3(2):184-206.

34. Min H, Park B-I. Evaluating the inter-temporal efficiency trends of international container terminals using data envelopment analysis. Int J Integr Supply Manag. 2005;1(3):258-277. http://dx.doi.org/10.1504/IJISM.2005.005950

35. Pjevcevic D, Radonjic A, Hrle Z, Colic V. DEA window analysis for measuring port efficiencies in Serbia. Promet-Traffic Transp. 2012;24(1):63-72. http:// dx.doi.org/10.7307/ptt.v24i1.269

36. Cullinane K, Wang T-F. The efficiency of European container ports: A crosssectional data envelopment analysis. Int J Logist Res Appl. 2006;9(1):19-31. http://dx.doi.org/10.1080/13675560500322417

37. Van Dyck GK. Assessment of port efficiency in West Africa using data envelopment analysis. Am J Ind Bus Manag. 2015;5(April):208-218. http:// dx.doi.org/10.4236/ajibm.2015.54023

38. Hummels D, Schaur G. Time as a trade barrier. Am Econ Rev Am Econ Assoc 2013;103(7):2935-2959. https://doi.org/10.1257/aer.103.7.2935

39. Nordquist M, Nandan S, Rosenne S, editors. United Nations Convention on the Law of the Sea 1982. Leiden: Martinus Nijhoff; 2011.

40. Despić 0, Despić M, Paradi JC. DEA-R: Ratio-based comparative efficiency model, its mathematical relation to DEA and its use in applications. J Product Anal. 2007;28:33-44. http://dx.doi.org/10.1007/s11123-007-0050-x

41. Wu J, Liang N. Performances and benchmarks of container ports using data envelopment analysis. Int J Shipp Transp Logist. 2009;1(3):295. http:// dx.doi.org/10.1504/IJSTL.2009.027536

42. Charnes A, CooperWW, Rhodes E. Measuring the efficiency of decision making units. Eur J Oper Res. 1978;2(6):429-444. https://doi.org/10.1016/03772217(78)90138-8

43. Jahanshahloo GR, Soleimani-damaneh M, Mostafaee A. A simplified version of the DEA cost efficiency model. Eur J Oper Res. 2008;184(2):814-815. http://dx.doi.org/10.1016/j.ejor.2006.11.043

44. Andersen $P$, Petersen NC. A procedure for ranking efficient units in data envelopment analysis. Manage Sci. 1993;39(10):1261-1264. http://dx.doi. org/10.1287/mnsc.39.10.1261

45. Scheel H. EMS: Efficiency measurement system. A data envelopment analysis (DEA) software [software on the Internet]. c2000 [cited 2015 Jan 13]. Available from: http://www.holger-scheel.de/ems/\#down

46. The World Bank. Doing business: Measuring business regulation [homepage on the Internet]. c2014 [cited 2015 Feb 12]. Available from: http://www. doingbusiness.org/data/exploretopics/trading-across-borders

47. United Nations. UN trade statistics [homepage on the Internet]. c2014 [cited 2015 Feb 15]. Available from: http://unstats.un.org/unsd/trade/data/tables. asp\#annual

48. Peter $P$, Fedderke J, Luiz J. An analysis of economic infrastructure investment in South Africa. S Afr J Econ. 2005;73(2):211-228. http://dx.doi. org/10.1111/j.1813-6982.2005.00014.x

49. The World Bank. Business regulations. In: Doing business in landlocked economies. Washington DC: World Bank Group; 2009

50. Sachs JD, Warner A, Åslund A, Fischer S. Economic reform and the process of global integration. Brookings Pap Econ Act. 1995;1:1-118. http://dx.doi. org/ $10.2307 / 2534573$ 